\title{
Analysis of the accuracy of Z-scores of non- invasive prenatal testing for fetal Trisomies 13,18 , and 21 that employs the ion proton semiconductor sequencing platform
}

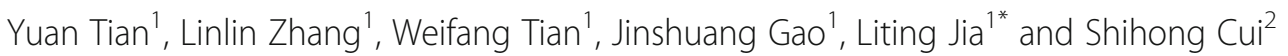

\begin{abstract}
Background: Non-invasive prenatal testing (NIPT) is frequently being used to screen for trisomies 13,18 and 21 for prenatal diagnosis. However, NIPT performs poorly when compared with invasive testing and thus should not be used to diagnose trisomies. The result of NIPT for an individual woman in most genome-wide methods is calculated as a Z-score. The aim of this study was to assess the correlation between Z-scores of NIPT results and the accuracy of non-invasive prenatal testing.

Results: We evaluated 108 pregnant women with positive NIPT results, which were validated through karyotype analysis of amniotic fluid puncture by means of sequencing, bioinformatics analysis, and follow-up. Utilizing the ion proton semiconductor sequencing platform, we report a performance evaluation of NIPT-positive results at Third Affiliated Hospital of Zhengzhou University of Henan Province, China, by classifying Z-scores as $3 \leq Z<5,5 \leq Z<9$ and $Z \geq 9$. The findings indicate that positive NIPT results at $Z \geq 9$ have a higher accuracy compared with positive NIPT results at $5 \leq Z<9$ and $3 \leq Z<5$.
\end{abstract}

Conclusions: The findings show that Z-scores of NIPT results are closely related to the accuracy of non-invasive prenatal testing. However, false-positive NIPT results at $3 \leq Z<5$ may occur due to confined placental mosaicism (CPM).

Keywords: Non-invasive prenatal testing (NIPT), False positive, Confined placental mosaicism (CPM), Trisomies

\section{Background}

Non-invasive prenatal testing (NIPT) is frequently being applied to screen for trisomies 13, 18 and 21 for prenatal diagnosis. Due to its simple operation and avoidance of amniocentesis, NIPT, as opposed to invasive procedures (chorionic villus sampling (CVS) or amniotic fluid), is regarded as the first choice when screening is required for fetal assessment in pregnant women. Indeed, NIPT is an attractive option because it is procedurally safe for both mother and fetus, can be conducted as early as 10 weeks of gestation, and is highly accurate [1]. Nonetheless, NIPT performs poorly when compared with

\footnotetext{
* Correspondence: jialiting@sina.com

'Department of Clinical Laboratory, The Third Affiliated Hospital of Zhengzhou University, No. 7 Front Kangfu Street, Er'qi District, Zhengzhou 450052, China

Full list of author information is available at the end of the article
}

invasive testing and thus should not be used to diagnose trisomies [2]. Confined placental mosaicism (CPM), which can occur through a mitotic nondisjunction event or through aneuploidy rescue, has one of the greatest obstacles on NIPT result confirmation [3]. CPM is a phenomenon whereby a cytogenetic abnormality, most often trisomy, is confined to the placenta [4]. False-positive NIPT results can occur due to CPM.

Recent NIPT technologies are predominantly based on next-generation sequencing (NGS) [5]. NGS enables rapid and effective clinical testing such as the IONA ${ }^{\circ}$ test, which uses the Ion proton semiconductor sequencing platform, has a turnaround time, from the start of sample processing to the result, of 3 days [6]. For most genome-wide methods, the result of NIPT for an individual woman is calculated as a Z-score, where the 
individual sample is compared with a control group of normal (diploid) samples. In some research, an a posteriori risk (PPR) calculator is used to more accurately express the true likelihood of carrying a fetus with a trisomy. For an individual woman, a positive NIPT result with a sensitivity and specificity of more than $99 \%$ does not necessarily indicate that she actually has more than a $99 \%$ chance of carrying a fetus with a trisomy. The true likelihood depends not only on the NIPT result but also on the prevalence of the anomaly in the population to which she belongs [7], which is expressed as an a priori risk. Thus, to properly counsel women about a positive result by cell-free fetal DNA screening, it can be useful to express the result as a personalized PPR, which takes the woman's a priori risk into account. Research shows that PPR is effectively independent under all conditions for Z-scores above 6, and high PPR for low a priori risk can only be reached at Z-scores> 5 [8].

In the present study, we report a performance evaluation of NIPT-positive results in our hospital by classifying $\mathrm{Z}$-scores as $3 \leq \mathrm{Z}<5, \quad 5 \leq \mathrm{Z}<9$ and $\mathrm{Z} \geq 9$. The results of our study indicate that positive NIPT results with $Z$-scores of $Z \geq 9$ have higher accuracy compared with positive NIPT results with Z-scores of $3 \leq \mathrm{Z}<5$ and $5 \leq \mathrm{Z}<9$.

\section{Methods}

\section{Patients}

Written informed consent was obtained from each patient. The study was a retrospective analysis of NIPT-positive results in singleton pregnancies from January 2015 to December 2017 at Third Affiliated Hospital of Zhengzhou University of Henan Province, China. Positive NIPT results would be validated through postpartum follow-up of patients, involving the results of karyotype analysis via amniotic fluid puncture, including trisomies 13, 18, and 21 (T21, T18 and T13); 108 cases were validated in this manner.

\section{Sequencing process}

Maternal peripheral blood ( $5 \mathrm{ml}$ ) was collected into an ethylenediaminetetraacetic acid (EDTA) tube at $12+0$ to $25+6$ weeks of gestation. The blood samples were stored at $4{ }^{\circ} \mathrm{C}$ immediately after collection. Plasma was isolated within $8 \mathrm{~h}$ through a two-step centrifugation protocol, after which the samples were stored at $-80{ }^{\circ} \mathrm{C}$. Cell-free DNA extraction, library construction, sequencing, and bioinformatics analysis were performed according to a previous study [6].

\section{Bioinformatics analysis}

Sequencing data were analyzed by using the ion proton semiconductor sequencing platform and software from Capitalbio Corporation. The binary hypothesis Z-score of particular chromosomes in each sample was determined, as reported previously [7]. To assess fetal risk of T21, T18 and T13, sample with a Z-score $\geq 3$ for these chromosomes was classified as positive. We classified the positive samples into three groups according to $\mathrm{Z}$-score $=5$ and $\mathrm{Z}=9$ among them. Group 1 contained samples with NIPT results of $3 \leq Z<5$. Group 2 contained samples with NIPT results of $5 \leq Z<9$. Group 3 contained samples with NIPT results of $Z \geq 9$.

\section{Karyotype analysis and amniotic fluid puncture}

For those with positive NIPT results, karyotype analysis and amniotic fluid puncture were recommended for validation. Amniotic fluid puncture was performed as routinely described; karyotype analysis was performed according to the International System for Human Cytogenetic Nomenclature guidelines [9].

\section{Follow-up}

Follow-up for NIPT-positive cases was performed via telephone. The follow-up duration was 56 days after delivery.

\section{Results}

\section{Patient characteristics}

A total of 21,114 pregnant women were tested by NIPT from 2015 to 2017, with 202 having positive results. According to follow-up, cases of induced labor that was not validated through other invasive methods were removed. Overall, 108 NIPT-positive women who were validated via karyotype analysis and amniotic fluid puncture, with a mean maternal age of 33.5 (19-48 years), were included in this study. Gestational age was from 12 weeks to $25+6$ weeks at blood sample collection. Because the fetal DNA fraction in NIPT needs to be higher than $4 \%$ for a singleton and $8 \%$ for twins, pregnant women tend to accept NIPT at more than 16 weeks to obtain a higher fetal fraction. As cases of NIPT-positive results should be validated through karyotype analysis and amniotic fluid puncture, we would suggest that the patients accept NIPT within 20 weeks. The patient characteristics are listed in Table 1.

\section{Relationship of NIPT-positive results group 1 with karyotype analysis and amniotic fluid puncture}

In total, 18 NIPT-positive cases were included in Group $1(3 \leq \mathrm{Z}<5)$; 15 cases with false-positive results were validated through karyotype analysis and amniotic fluid puncture. Conversely, 3 true-positive cases were validated through karyotype analysis and amniotic fluid puncture, with a positive predictive value (PPV) of only 16.67\%. The NIPT-positive cases in Group 1 are listed in Table 2. By analyzing the data of the 3 true-positive NIPT cases, we found that the fetal DNA fraction 
Table 1 Basic Characteristics of 108 NIPT-Positive Patients

\begin{tabular}{|c|c|}
\hline Characteristics & Numbers \\
\hline \multicolumn{2}{|c|}{ Maternal age(years) } \\
\hline$\leq 20$ & 1 \\
\hline $20-24$ & 5 \\
\hline $25-29$ & 31 \\
\hline $30-34$ & 21 \\
\hline $35-39$ & 35 \\
\hline $40-45$ & 13 \\
\hline$\geq 45$ & 2 \\
\hline Mean & 33.5 \\
\hline Range & 19-48 \\
\hline \multicolumn{2}{|c|}{ Gestation at NIPT tests(weeks) } \\
\hline $12-12+6$ & 4 \\
\hline $13-13+6$ & 9 \\
\hline $14-14+6$ & 5 \\
\hline $15-15+6$ & 8 \\
\hline $16-16+6$ & 17 \\
\hline $17-17+6$ & 14 \\
\hline $18-18+6$ & 14 \\
\hline $19-19+6$ & 17 \\
\hline $20-20+6$ & 5 \\
\hline $21-21+6$ & 6 \\
\hline $22-22+6$ & 2 \\
\hline $23-23+6$ & 5 \\
\hline $24-24+6$ & 0 \\
\hline $25-25+6$ & 2 \\
\hline
\end{tabular}

estimation for samples YC151439 and YC173711 was less than 4\%; the fetal DNA fraction estimation for sample YC174141 was $6.4 \%$, which was less than $8 \%$.

\section{Relationship of NIPT-positive results for group 2 with karyotype analysis and amniotic fluid puncture}

A total of 34 NIPT-positive cases were in Group 2 ( $5 \leq$ $\mathrm{Z}<9$ ). Four cases of false positivity were validated through karyotype analysis and amniotic fluid puncture. In contrast, 30 true-positive results were validated via karyotype analysis and amniotic fluid puncture, with a PPV of $88.24 \%$. Table 3 lists the positive NIPT cases in Group 2.

Based on analysis of the data for the 4 false-positive cases, sample YC167160 was validated as CPM through karyotype analysis and amniotic fluid puncture (Table 3). Sample YC160356 was possibly affected by chromosome duplication from the maternal fragment (Fig. 1). The false-positive NIPT result for samples YC166422 and
Table 2 The 18 NIPT-Positive Cases in Group $1(3 \leq Z<5)$

\begin{tabular}{|c|c|c|c|c|}
\hline No. & Sample ID & Z-scores & NIPT results & Fetal karyotype \\
\hline 1 & YC150550 & 3.330 & $\mathrm{~T} 21$ & $46, \mathrm{XN}$ \\
\hline 2 & YC150816 & 4.342 & $\mathrm{~T} 13$ & $46, \mathrm{XN}$ \\
\hline 3 & YC151439 & 3.643 & $\mathrm{~T} 21$ & $47, X N+21$ \\
\hline 4 & YC161217 & 4.056 & $\mathrm{~T} 13$ & $46, X N$ \\
\hline 5 & YC163341 & 4.778 & $\mathrm{~T} 13$ & $46, \mathrm{XN}$ \\
\hline 6 & YC164267 & 3.968 & $\mathrm{~T} 13$ & $46, \mathrm{XN}$ \\
\hline 7 & YC165157 & 3.392 & $\mathrm{~T} 21$ & $46, \mathrm{XN}$ \\
\hline 8 & YC165602 & 3.362 & $\mathrm{~T} 18$ & $46, \mathrm{XN}$ \\
\hline 9 & YC167031 & 3.075 & $\mathrm{~T} 21$ & $46, \mathrm{XN}$ \\
\hline 10 & YC171503 & 3.207 & $\mathrm{~T} 21$ & $46, \mathrm{XN}$ \\
\hline 11 & YC173711 & 4.951 & $\mathrm{~T} 21$ & $47, X N+21$ \\
\hline 12 & YC174141 & 3.242 & T21 & $47, X N+21$ \\
\hline 13 & YC175988 & 3.713 & $\mathrm{~T} 21$ & $46, \mathrm{XN}$ \\
\hline 14 & YC175996 & 4.111 & $\mathrm{~T} 18$ & $46, \mathrm{XN}$ \\
\hline 15 & YC176477 & 3.351 & T18 & $46, \mathrm{XN}$ \\
\hline 16 & YC176775 & 3.620 & $\mathrm{~T} 21$ & $46, \mathrm{XN}$ \\
\hline 17 & YC177355 & 3.263 & T21 & $46, \mathrm{XN}$ \\
\hline 18 & YC177383 & 3.697 & $\mathrm{~T} 13$ & $46, \mathrm{XN}$ \\
\hline
\end{tabular}

YC177345 might have resulted from a small region of chromosome duplication (Fig. 2 and Fig. 3).

\section{Relationship of NIPT-positive results for group 3 with karyotype analysis and amniotic fluid puncture}

Group $3(Z \geq 9)$ comprised 56 cases of NIPT positivity. Only one false-positive case was validated by karyotype analysis and amniotic fluid puncture. For sample YC175377, a unique sample with a false-positive result, a unique sample with a false-positive result, the discordant NIPT result was caused by a vanished twin, as revealed by NIPT in the 4 weeks during follow-up. In total, 55 true-positive cases were validated through karyotype analysis and amniotic fluid puncture; the PPV was 98.12\%. The positive NIPT cases in Group 3 are listed in Table 4.

Among all of the 21,114 patients accepting NIPT, two cases of false-negative NIPT results were found. However, those with false-negative NIPT results refused to accept further validation of aborted tissue.

\section{Discussion}

NIPT has been widely used in the last few years for prenatal screening of T21, T18 and T13. Although PPR calculation suggests that high PPR for low a priori risk can only be reached at Z-scores $>5$ [7], large-scale clinical studies to validate the hypothesis are lacking. The present study including 108 NIPT-positive cases was 
Table 3 The 34 NIPT-Positive Cases in Group $2(5 \leq Z<9)$

\begin{tabular}{|c|c|c|c|c|}
\hline No. & Sample ID & Z-scores & NIPT results & Fetal karyotype \\
\hline 1 & YC150539 & 5.570 & $\mathrm{~T} 21$ & $47, X N+21$ \\
\hline 2 & YC150431 & 5.960 & $\mathrm{~T} 18$ & $47, X N+18$ \\
\hline 3 & YC150725 & 7.463 & T21 & $47, X N+21$ \\
\hline 4 & YC152284 & 8.249 & $\mathrm{~T} 21$ & $47, X N+21$ \\
\hline 5 & YC153184 & 8.532 & $\mathrm{~T} 21$ & $47, X N+21$ \\
\hline 6 & YC160356 & 8.830 & T21 & $46, \mathrm{XN}$ \\
\hline 7 & YC161880 & 8.188 & T21 & $47, X N+21$ \\
\hline 8 & YC163276 & 5.467 & $\mathrm{~T} 18$ & $47, X N+18$ \\
\hline 9 & YC163808 & 6.104 & $\mathrm{~T} 21$ & $47, X N+21$ \\
\hline 10 & YC164065 & 5.219 & $\mathrm{~T} 18$ & $47, X N+18$ \\
\hline 11 & YC164811 & 8.489 & T21 & $47, \mathrm{XN}+21$ \\
\hline 12 & YC165074 & 6.677 & T21 & $47, X N+21$ \\
\hline 13 & YC165729 & 5.944 & $\mathrm{~T} 21$ & $47, X N+21$ \\
\hline 14 & YC166180 & 6.150 & $\mathrm{~T} 21$ & $47, X N+21$ \\
\hline 15 & YC166202 & 6.220 & $\mathrm{~T} 18$ & $47, X N+18$ \\
\hline 16 & YC166253 & 5.931 & $\mathrm{~T} 21$ & $\begin{array}{l}46 X X+21 \\
\operatorname{der}(14 ; 15)(q 10, q 10)\end{array}$ \\
\hline 17 & YC166422 & 8.945 & $\mathrm{~T} 13$ & $46, \mathrm{XN}$ \\
\hline 18 & YC167160 & 5.710 & $\mathrm{~T} 18$ & $\begin{array}{l}46, X X / 47, X X \\
+18(28: 2)\end{array}$ \\
\hline 19 & YC167331 & 7.790 & $\mathrm{~T} 21$ & $47, X N+21$ \\
\hline 20 & YC168025 & 6.840 & $\mathrm{~T} 21$ & $47, X N+21$ \\
\hline 21 & YC170096 & 8.280 & $\mathrm{~T} 21$ & $47, X N+21$ \\
\hline 22 & YC171234 & 6.119 & $\mathrm{~T} 21$ & $47, X N+21$ \\
\hline 23 & YC171535 & 7.273 & T21 & $47, X N+21$ \\
\hline 24 & YC171540 & 6.019 & $\mathrm{~T} 21$ & $47, X N+21$ \\
\hline 25 & YC173331 & 5.330 & T21 & $47, X N+21$ \\
\hline 26 & YC173539 & 7.514 & T21 & $47, X N+21$ \\
\hline 27 & YC173759 & 6.834 & T21 & $47, X N+21$ \\
\hline 28 & YC175051 & 6.908 & T21 & $47, X N+21$ \\
\hline 29 & YC175492 & 8.646 & $\mathrm{~T} 18$ & $47, \mathrm{XN}+18$ \\
\hline 30 & YC175694 & 6.704 & $\mathrm{~T} 13$ & $47, X N+13$ \\
\hline 31 & YC176740 & 7.803 & $\mathrm{~T} 21$ & $47, X N+21$ \\
\hline 32 & YC177345 & 5.178 & $\mathrm{~T} 21$ & $46, \mathrm{XN}$ \\
\hline 33 & YC176881 & 5.566 & $\mathrm{~T} 21$ & $47, X N+21$ \\
\hline 34 & YC177644 & 8.523 & $\mathrm{~T} 21$ & $47, X N+21$ \\
\hline
\end{tabular}

performed to investigate the relationship between NIPT Z-scores and accuracy of trisomy 13, 18, and 21 diagnosis.

The PPV is much more meaningful to clinicians and patients than the commonly reported measures of sensitivity and specificity [10]. The PPV referred to here is a population-based figure that reports the chance prior to testing that an abnormal test result is actually reflective of the karyotype of the fetus. Except for the PPV, neither sensitivity nor specificity reflects the prevalence of a disorder in the population [10]. Based on the results of the present study, a sample with $Z \geq 9$ has higher accuracy than does a sample with $3 \leq \mathrm{Z}<5$ or $5 \leq \mathrm{Z}<9$. Although the PPV rate in Group 2 (88.24\%) was apparently higher that of Group $1(16.67 \%)$, this approach cannot be used for diagnosis because of the relatively high false-positive rate $(11.76 \%)$. Nonetheless, positive results at $Z \geq 9$ are significant for diagnosing trisomies 13, 18 and 21; However, karyotype analysis is necessary for validating trisomies due to the exist of sample YC175377, whose discordant NIPT result may be caused by a vanished twin. There are many biological reasons for discordant results that can be of either fetal or maternal origin. Contributing fetal factors include an insufficient or absent fetal fraction, confined placental mosaicism and the presence of a vanishing twin [11]. For example, Hall AL et al. reported a case that confirmed positive cell-free fetal DNA (cffDNA) testing for trisomy 13, revealing confined placental mosaicism [12]. In addition, Chen C et al. reported a pregnancy with discordant fetal and placental chromosome 18 aneuploidies, as revealed by invasive and noninvasive prenatal diagnoses [13].

CPM is one of the major factors causing false positivity. cffDNA originates from chorionic villi in the placenta, where the constant turnover of cytotrophoblasts induces apoptosis and cffDNA release into the maternal blood. The cytotrophoblast layer of chorionic villi is not always representative of the fetus, as it is derived from the trophoblast of the blastocyst; in contrast, the fetus is derived from the inner cell mass (epiblast) [14]. Postzygotic mitotic division errors in chromosomally normal

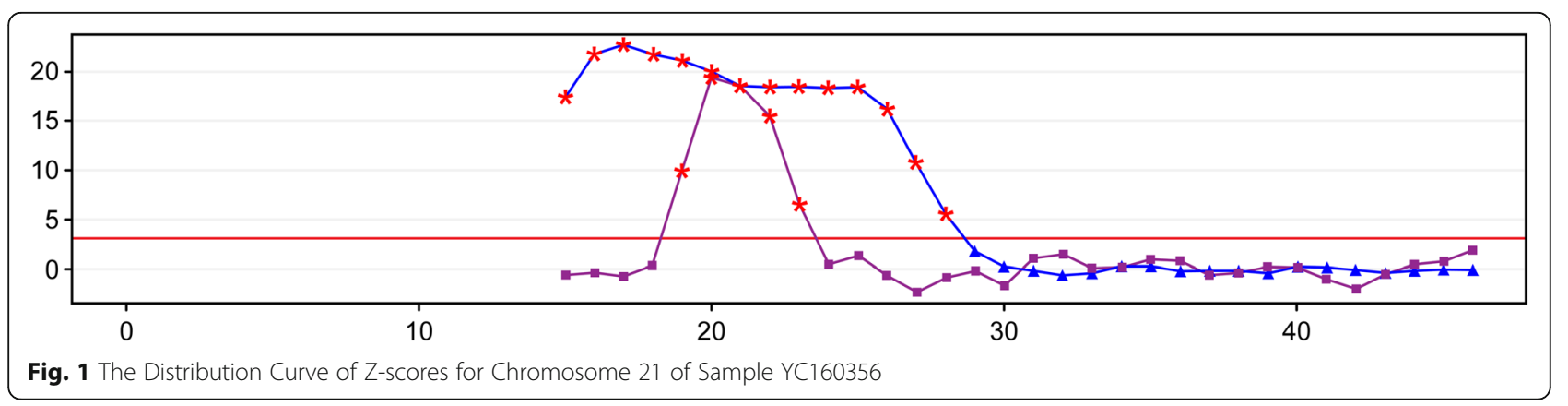




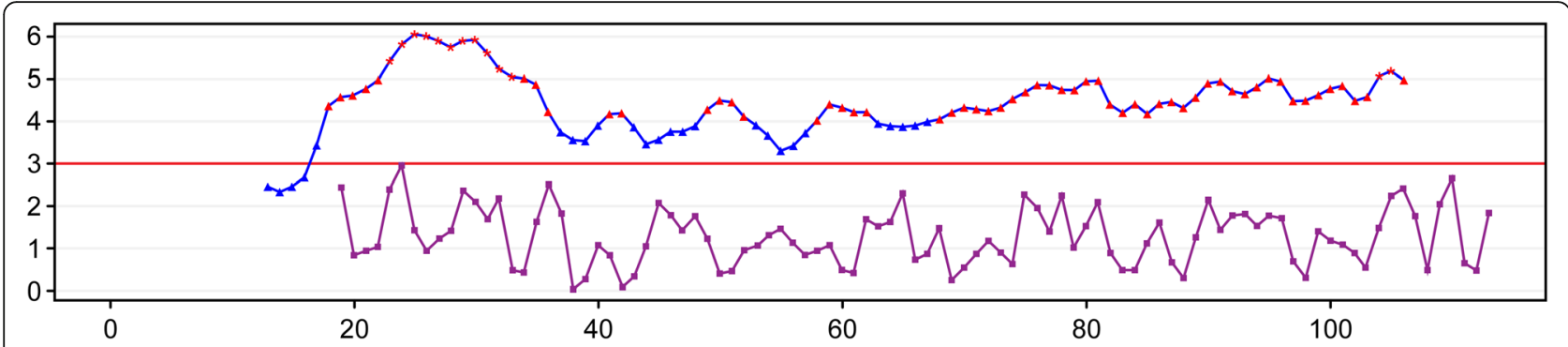

Fig. 2 The Distribution Curve of Z-scores for Chromosome 13 of Sample YC166422

and abnormal conceptuses will lead to chromosomal mosaicism [15]. Most often, mosaicism is characterized as CPM, in which the abnormal cell line is confined to the cytotrophoblast and/or the mesenchymal core of the chorion villi, whereas the fetus has a normal karyotype [15]. If abnormal cells are restricted to the cytotrophoblast layer and are not present in the mesenchymal core or fetus, such a case is categorized CPM and depending on the extent of mosaicism, will possibly cause a false-positive NIPT result. According to the above, we suggest that the occurrence of CPM may slightly elevate a Z-score for NIPT, higher than 3 but lower than 5 .

In addition, estimation of the fetal DNA fraction is important for the accuracy of NIPT results. The definition of the fetal fraction of circulating cell-free DNA in maternal blood is the amount of cffDNA divided by the amount of total cell-free DNA. The circulating cell-free DNA (cfDNA) in a pregnant woman is a mixture of predominant maternal DNA derived from her hematopoietic system and fetal DNA released through apoptosis of cytotrophoblast cells during fetal development [16]. A fetal DNA concentration of less than $4 \%$ in a maternal plasma sample would suggest a potential issue present in the quality control (QC) step [17]. Methods for calculating the fetal fraction differ between laboratories. We are aware of six different methods based on methylation [18], single-nucleotide polymorphisms [19], quantitative polymerase chain reaction of the Y-chromosome (only for male fetuses) [20], autosomal regional read counts calculated by SeqFF [21], differences in length between cffDNA and maternal cffDNA [21] and single reads nucleosome-based fetal fraction [22]. The fetal fraction is also related to maternal weight and body mass index. For example, the increased turnover of adipocytes in obese women increases the amount of maternal cell-free DNA and decreases the cffDNA fraction [23]. Furthermore, gestational age influences the fetal fraction. Some research has found that levels of cffDNA increase at $0.1 \%$ per week between 10 and 21 weeks of gestation and at $1 \%$ per week beyond 21 weeks of gestation [24]. Because the limited amount of fetal DNA molecules to be detected and analyzed may give rise to a false-negative result, we deduce that the Z-scores of samples YC151439, YC173711 and YC174141 were less than 5 because of the estimation of a low fetal DNA fraction.

Regardless, maternally derived chromosomal abnormalities (likely also submicroscopic abnormalities) constitute a rare case of maternal occult malignancy and usually cause false-positive results [25]. Our study validated the hypothesis regarding the false-positive NIPT result for sample YC160356 (Fig. 1).

\section{Conclusions}

NIPT is feasible for prenatal screening of T13, T18 and T21, with higher sensitivity and specificity compared with conventional methods. However, Z-scores of NIPT results are closely related to the accuracy of non-invasive prenatal

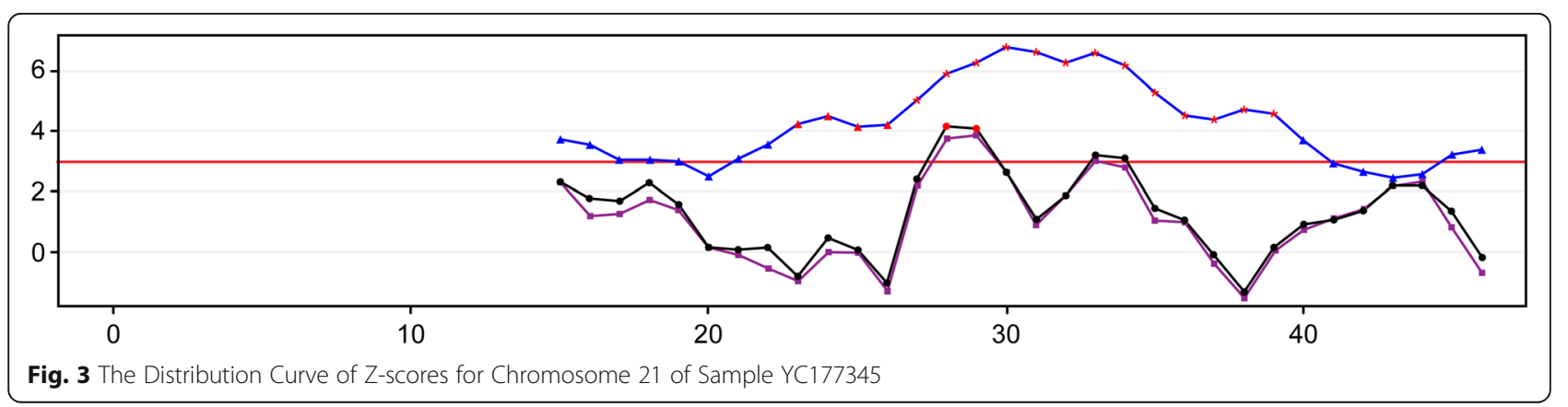


Table 4 The 56 NIPT-Positive Cases in Group 2 ( $Z \geq 9$ )

\begin{tabular}{|c|c|c|c|c|}
\hline No. & Sample ID & Z-scores & NIPT results & Fetal karyotype \\
\hline 1 & YC151198 & 11.203 & T21 & $47, X N+21$ \\
\hline 2 & YC151297 & 11.605 & T21 & $47, X N+21$ \\
\hline 3 & YC151374 & 9.306 & $\mathrm{~T} 21$ & $47, X N+21$ \\
\hline 4 & YC151424 & 19.541 & T21 & $47, X N+21$ \\
\hline 5 & YC151577 & 14.882 & $\mathrm{~T} 21$ & $47, X N+21$ \\
\hline 6 & YC151725 & 12.367 & T21 & $47, X N+21$ \\
\hline 7 & YC152585 & 18.082 & T21 & $47, X N+21$ \\
\hline 8 & YC153464 & 10.126 & T21 & $47, X N+21$ \\
\hline 9 & YC153533 & 11.864 & $\mathrm{~T} 21$ & $47, X N+21$ \\
\hline 10 & YC160344 & 14.298 & $\mathrm{~T} 21$ & $47, X N+21$ \\
\hline 11 & YC161058 & 10.8 & $\mathrm{~T} 21$ & $47, X N+21$ \\
\hline 12 & YC161066 & 21.457 & $\mathrm{~T} 21$ & $47, X N+21$ \\
\hline 13 & YC161368 & 13.275 & T21 & $47, X N+21$ \\
\hline 14 & YC162688 & 9.707 & T21 & $47, X N+21$ \\
\hline 15 & YC162822 & 16.21 & $\mathrm{~T} 18$ & $47, X N+18$ \\
\hline 16 & YC162943 & 11.347 & $\mathrm{~T} 21$ & $47, X N+21$ \\
\hline 17 & YC163223 & 13.694 & T21 & $47, X N+21$ \\
\hline 18 & YC163261 & 13.627 & T21 & $47, X N+21$ \\
\hline 19 & YC163310 & 13.977 & $\mathrm{~T} 18$ & $47, X N+18$ \\
\hline 20 & YC163400 & 11.603 & T13 & $47, X N+13$ \\
\hline 21 & YC164204 & 10.546 & $\mathrm{~T} 21$ & $47, X N+21$ \\
\hline 22 & YC164355 & 11.135 & T21 & $47, X N+21$ \\
\hline 23 & YC164722 & 13.955 & $\mathrm{~T} 21$ & $47, X N+21$ \\
\hline 24 & YC164999 & 13.661 & T21 & $47, X N+21$ \\
\hline 25 & YC165003 & 11.899 & T18 & $47, X N+18$ \\
\hline 26 & YC165723 & 10.192 & T21 & $47, X N+21$ \\
\hline 27 & YC165823 & 10.346 & T18 & $47, \mathrm{XN}+18$ \\
\hline 28 & YC165859 & 11.962 & T18 & $47, X N+18$ \\
\hline 29 & YC166626 & 9.374 & $\mathrm{~T} 13$ & $47, X N+13$ \\
\hline 30 & YC167544 & 11.253 & T18 & $47, X N+18$ \\
\hline 31 & YC168149 & 11.004 & $\mathrm{~T} 21$ & $47, X N+21$ \\
\hline 32 & YC170133 & 12.085 & T21 & $47, X N+21$ \\
\hline 33 & YC170411 & 12.536 & $\mathrm{~T} 21$ & $47, X N+21$ \\
\hline 34 & YC170724 & 10.017 & $\mathrm{~T} 21$ & $47, X N+21$ \\
\hline 35 & YC170829 & 12.456 & T21 & $47, X N+21$ \\
\hline 36 & YC170974 & 11.555 & T21 & $47, X N+21$ \\
\hline 37 & YC171134 & 9.885 & T21 & $47, X N+21$ \\
\hline 38 & YC171423 & 11.41 & T21 & $47, X N+21$ \\
\hline 39 & YC172015 & 18.693 & T21 & $47, X N+21$ \\
\hline 40 & YC172946 & 20.224 & T21 & $47, X N+21$ \\
\hline 41 & YC173326 & 9.674 & T21 & $47, X N+21$ \\
\hline 42 & YC173370 & 17.431 & $\mathrm{~T} 21$ & $47, X N+21$ \\
\hline 43 & YC173573 & 26.587 & T21 & $47, X N+21$ \\
\hline 44 & YC173742 & 9.054 & T21 & $47, X N+21$ \\
\hline
\end{tabular}

Table 4 The 56 NIPT-Positive Cases in Group 2 ( $Z \geq 9$ ) (Continued)

\begin{tabular}{lllll}
\hline No. & Sample ID & Z-scores & NIPT results & Fetal karyotype \\
\hline 45 & YC174011 & 13.767 & T21 & $47, \mathrm{XN}+21$ \\
46 & YC174110 & 11.488 & T21 & $47, \mathrm{XN}+21$ \\
47 & YC174589 & 16.765 & T21 & $47, \mathrm{XN}+21$ \\
48 & YC175377 & 12.367 & T18 & $46, \mathrm{XN}$ \\
49 & YC175406 & 11.424 & T21 & $47, \mathrm{XN}+21$ \\
50 & YC175583 & 9.772 & T21 & $47, \mathrm{XN}+21$ \\
51 & YC175824 & 13.609 & T21 & $47, \mathrm{XN}+21$ \\
52 & YC175903 & 12.095 & T21 & $47, \mathrm{XN}+21$ \\
53 & YC176469 & 11.443 & T18 & $47, \mathrm{XN}+18$ \\
54 & YC177386 & 25.448 & T18 & $47, \mathrm{XN}+18$ \\
55 & YC176915 & 12.225 & T21 & $47, \mathrm{XN}+21$ \\
56 & YC178093 & 18.509 & T18 & $47, \mathrm{XN}+18$ \\
\hline
\end{tabular}

testing that employs the ion proton semiconductor sequencing platform. NIPT results with low Z-scores should not be used for diagnosis, which should be performed using invasive testing. However, the relationship between Z-scores of NIPT and CPM lacks validation by clinical trials due to the influence of chorionic villi in the placenta.

\section{Abbreviations}

cfDNA: Circulating cell-free DNA; CPM: Confined placental mosaicism; EDTA: Ethylenediaminetetraacetic acid; NIPT: Non-invasive prenatal testing; QC: Quality control

\section{Author contributions}

YT performed the bioinformatics analysis and drafted the manuscript. LZ performed karyotype analysis, amniotic fluid puncture and follow-up. WT recruited the patients, provided blood samples and clinical data for each participant and helped to draft the manuscript. JG performed the NIPT. $L J$ performed the statistical analysis and helped to draft the manuscript. SC took a plan for the research. All authors read and approved the final manuscript.

\section{Funding}

National Key Research and Development Program of China,2016YFC1000700,2016YFC1000703.

\section{Availability of data and materials}

The datasets obtained in this study are available from the corresponding author.

\section{Ethics approval and consent to participate}

The study was approved by the Ethics committee of Third Affiliated Hospital of Zhengzhou University, where it was conducted. Each patient signed informed consent prior to study enrollment.

\section{Consent for publication}

All the participants accepted with the initial written informed consent the possibility that the results of this study could be published.

Competing interests

The authors declare that they have no competing interests.

\section{Publisher's Note}

Springer Nature remains neutral with regard to jurisdictional claims in published maps and institutional affiliations. 


\section{Author details}

'Department of Clinical Laboratory, The Third Affiliated Hospital of Zhengzhou University, No. 7 Front Kangfu Street, Er'qi District, Zhengzhou 450052, China. ${ }^{2}$ Department of gynaecology and obstetrics, The Third Affiliated Hospital of Zhengzhou University, No. 7 Front Kangfu Street, Er'qi District, Zhengzhou 450052, China.

Received: 27 March 2018 Accepted: 13 August 2018

Published online: 25 August 2018

\section{References}

1. Minear MA, Lewis C, Pradhan S, et al. Global perspectives on clinica adoption of NIPT. Prenat Diagn. 2015;35(10):959-67.

2. Lau TK, Cheung SW, Lo PS, et al. Non-invasive prenatal testing for feta chromosomal abnormalities by low-coverage whole-genome sequencing of maternal plasma DNA: review of 1982 consecutive cases in a single center. Ultrasound Obstet Gynecol. 2014;43(3):254-64.

3. Mardy A, Wapner RJ. Confined placental mosaicism and its impact on confirmation of NIPT results. Am J Med Genet C Semin Med Genet. 2016; 172(2):118-22

4. Kalousek DK, Vekemans M. Confined placental mosaicism. J Med Genet. 1996:33(7):529-33.

5. Vrachnis N, Vlachadis N, Creatsas G. DNA sequencing versus standard prenatal aneuploidy screening. N Engl J Med. 2014;371(6):578.

6. Papageorghiou AT, Khalil A, Forman M, et al. Clinical evaluation of the IONA test: a non-invasive prenatal screening test for trisomies 21, 18 and 13. Ultrasound Obstet Gynecol. 2016;47(2):188-93.

7. Morain S, Greene MF, Mello MM. A new era in noninvasive prenatal testing. N Engl J Med. 2013;369(6):499-501.

8. Sikkema-Raddatz B, Johansson LF, de Boer EN, et al. NIPTRIC: an online tool for clinical interpretation of non-invasive prenatal testing (NIPT) results. Sci Rep. 2016;6:38359.

9. Gonzalez GJ, Meza-Espinoza JP. Use of the international system for human cytogenetic nomenclature (ISCN). BLOOD. 2006;108(12):3952-3.

10. Meck JM, Kramer DE, Matyakhina L, et al. Noninvasive prenatal screening for aneuploidy: positive predictive values based on cytogenetic findings. Am J Obstet Gynecol. 2015;213(2):211-4.

11. Grati FR. Implications of fetoplacental mosaicism on cell-free DNA testing: a review of a common biological phenomenon. Ultrasound Obstet Gynecol. 2016;48(4):415-23.

12. Hall $A L$, Drendel $H M$, Verbrugge $J$, et al. Positive cell-free fetal DNA testing for trisomy 13 reveals confined placental mosaicism. GENET MED. 2013; 15(9):729-32.

13. Chen C, Cram DS, Xie F, et al. A pregnancy with discordant fetal and placental chromosome 18 aneuploidies revealed by invasive and noninvasive prenatal diagnosis. Reprod BioMed Online. 2014;29(1):136-9.

14. Bianchi DW, Wilkins-Haug LE, Enders AC, et al. Origin of extraembryonic mesoderm in experimental animals: relevance to chorionic mosaicism in humans. Am J Med Genet. 1993:46(5):542-50.

15. Malvestiti F, Agrati C, Grimi B, et al. Interpreting mosaicism in chorionic villi: results of a monocentric series of 1001 mosaics in chorionic villi with follow-up amniocentesis. Prenat Diagn. 2015;35(11):1117-27.

16. Peng $X \mathrm{~L}$, Jiang P. Bioinformatics Approaches for Fetal DNA Fraction Estimation in Noninvasive Prenatal Testing. Int J Mol Sci. 2017:18(2).

17. Canick JA, Palomaki GE, Kloza EM, et al. The impact of maternal plasma DNA fetal fraction on next generation sequencing tests for common fetal aneuploidies. Prenat Diagn. 2013;33(7):667-74.

18. Poon LL, Leung TN, Lau TK, et al. Differential DNA methylation between fetus and mother as a strategy for detecting fetal DNA in maternal plasma. Clin Chem. 2002:48(1):35-41.

19. Dar P, Curnow KJ, Gross SJ, et al. Clinical experience and follow-up with large scale single-nucleotide polymorphism-based noninvasive prenatal aneuploidy testing. Am J Obstet Gynecol. 2014;211(5):521-7.

20. Hudecova I, Sahota D, Heung MM, et al. Maternal plasma fetal DNA fractions in pregnancies with low and high risks for fetal chromosomal aneuploidies. PLoS One. 2014;9(2):e88484.

21. Kim SK, Hannum G, Geis J, et al. Determination of fetal DNA fraction from the plasma of pregnant women using sequence read counts. Prenat Diagn. 2015;35(8):810-5.
22. Straver R, Oudejans CB, Sistermans EA, et al. Calculating the fetal fraction for noninvasive prenatal testing based on genome-wide nucleosome profiles. Prenat Diagn. 2016;36(7):614-21.

23. Haghiac M, Vora NL, Basu S, et al. Increased death of adipose cells, a path to release cell-free DNA into systemic circulation of obese women. Obesity (Silver Spring). 2012;20(11):2213-9.

24. Wang E, Batey A, Struble C, et al. Gestational age and maternal weight effects on fetal cell-free DNA in maternal plasma. Prenat Diagn. 2013; 33(7):662-6.

25. Bianchi DW, Chudova D, Sehnert AJ, et al. Noninvasive prenatal testing and incidental detection of occult maternal malignancies. JAMA. 2015; $314(2): 162-9$
Ready to submit your research? Choose BMC and benefit from:

- fast, convenient online submission

- thorough peer review by experienced researchers in your field

- rapid publication on acceptance

- support for research data, including large and complex data types

- gold Open Access which fosters wider collaboration and increased citations

- maximum visibility for your research: over $100 \mathrm{M}$ website views per year

At BMC, research is always in progress.

Learn more biomedcentral.com/submissions 